\title{
К МЕТОДИКЕ ПАЛИНОЛОГИЧЕСКИХ ИССЛЕДОВАНИЙ ОТЛОЖЕНИЙ МЕЖЛЕДНИКОВЫХ И ЛЕДНИКОВЫХ ЭПОХ НА ПРИМЕРЕ РАЗРЕЗА КОНЕВИЧА В СМОЛЕНСКОЙ ОБЛАСТИ
}

Палинологический метод - один из наиболее широко применяемых в стратиграфии и палеогеографии. Исследованию подвергаются отложения различных генетических типов как межледниковых, так и ледниковых времен. Но при этом не всегда учитываются существенные различия в формировании спорово-пыльцевых спектров таких разных палеогеографических эпох. Если во время межледниковий, в том числе в голоцене, пыльца и споры в отложениях практически всегда непосредственно отражают состав окружающей растительности, то присутствующий в отложениях ледниковых эпох «чужой» компонент в виде переотложенных пыльцы и спор искажает спектры и мешает восстановлению палеорастительностей и климатов. Пренебрежение фактом переотложения приводит к неправильной оценке ранга стратиграфических подразделений, к неправильной корреляции отложений и к неверным палеогеографическим выводам.

Методическая основа интерпретации таких смешанных спектров разработана в лаборатории спорово-пыльцевого анализа Института географин АН СССР (Гричук и др., 1969). Для разделения разновозрастных компонентов (инситной и переотложенной частей спектров) используется эколого-географический анализ определенных видов растений. Но в практике такой метод, к сожалению, не всегда заслуживает должного внимания. Возможно, это обусловлено еще отсутствием полного представления о масштабах переотложения во время оледенений, а также отсутствием полной осознанности ошибок, связанных с переотложением пыльцы и спор.

Наиболее полное представление о масштабах переотложения можно получить по таким опорным разрезам, которые охватывают отложения как межледниковой, так и ледниковой эпох. Такими являются верхнеплейстоценовые разрезы местностей Пасьва и Колешки на p. Ваге в Архангельской области (Лийвранд, 1981), разрезы СуурПрангли и Вяэна-Йэсуу (Раукас, Лийвранд, 1971 и др.). Относительно широкому временному диапазону позднего плейстоцена соответствуют и отложения в разрезе Коневича, подвергавшиеся местами сильному переотложению (рис. 1).

Разрез Коневича, предложенный нам для изучения Л. Н. Вознячуком, находится на 100 м выше устья ручейка Коневича, впадающего в Западную Двину у г. Велижа. Самые низы разреза представлены песком и озерной известью позднеледниковья московского оледенения (зона $M_{1}^{*}$ ). Буровато-серый мелкозернистый песок содержит очень

* Пыльцевая зона $M_{1}$ ранее считалась началом микулинского межледниковья (Гричук, 1961). Позже, вследствие уточнения критерия разграничения ледниковых и межледннковых флор, эти отложения были отнесены к позднеледниковью среднеплейстоценового московского оледенения (Гричук и др., 1969). 
много переотложенных дочетвертичных палиноморф - $600 \%$ сверх суммы четвертичных пыльцы и спор (рис. 2). Представлены они преимущественно карбоновыми спорами (Кедо, 1966), но встречаются некоторые мезозойские и девонские. Қарбоновые породы, выходы которых в настоящее время сохранились в московской синеклизе и в западной части Восточно-Европейской платформы, имели ранее, по всей вероятности, гораздо большее распространение. Эродирование богатых спорами карбоновых пород ледниками и их талыми водами обогатило морены и водноледниковые отложения этими спорами. В слое голубовато-серой извести на глубине $18,40-18,67$ м количество дочетвертичных палиноморф быстро уменьшается и превалирующими становятся четвертичные пыльца и споры. В их составе преобладают споры зеленых мхов $(45-75 \%)$. Количество пыльцы трав уменьшается вверх по интервалу от 20 до $6 \%$, а количество пыльцы древесных пород увеличивается в том же направлении от 5 до $10 \%$. Пыльцы древесных пород в этом слое слишком много из-за наличия переотложенной пыльцы межледниковых термофильных пород, особенно на глубнне 18,65 м. Характерно более высокое содержание переотложенной пыльцы ольхи $(55 \%)$, чем пыльцы лещины $(14 \%)$. Широколиственные породы представлены пыльцой вяза, липы и граба. Сходный состав переотложенной пыльцы в среднеплейстоценовых ледниковых отложениях обнаружен и в других опорных разрезах, что свидетельствует о переотложении их в основном из лихвинских межледниковых отложений (Лийвранд, 1982). Этот переотложенный комплекс пыльцы межледниковых термофильных пород зоны $M_{1}$ экологически несовместим с инситной частью спектров, несомненно перигляциальной растительности, которая вместе с пыльцой сосны и березы Betula nana L. представлена в основном лебедовыми (до 60\%) с Eurotia ceratoides (L.) С. А. М. и в меньшей степени полынью (до 30\%). Присутствуют Helianthemum sp. и Selaginella selaginoides (L.) Link.

Выше по разрезу, в слое желтовато-белой озерной извести (зона $\mathrm{M}_{2}$ ) переотложенная пыльца убывает и преобладающей становится пыльца сосны $(80-95 \%)$. Это говорит о распространении уже сомкнутых сосновых лесов в начале межледниковья. Типичная лесная растительность продуцирует в таком большом количестве инситной пыльцы, что переотложенные пыльцевые зерна становятся практически незаметными. В перигляциальных условиях, наоборот, продукция низкорослой травянистой и кустарниковой растительности пылинок столь скудна, что переотложенные палиноморфы часто становятся превалирующими. В начале формирования сапропелита в составе сосновых лесов появляются береза, дуб, вяз и лещина (зона $\mathrm{M}_{3}$ ).

Первая половина климатического оптимума микулинского межледниковья представлена максимально дубом $(30-70 \%)$ и вязом $(10-15 \%)$ со значительным участием лещины (зона $\left.M_{4}\right)$. Однако верхняя часть этой зоны уже затронута влиянием валдайского оледенения. Это прослеживается как по разрушениям и песчаным прослойкам в толще верхней части сапропелита, так и по искажениям закономерностей спорово-пыльцевых спектров. Пыльца и споры в песчаной прослойке на глубине 17,50 м явно происходят из эродированных отложений. Состав их отличается от состава зоны $\mathrm{M}_{4}$.

Выше по разрезу разрушение межледниковых отложений все заметнее. В интервале 16,60-17,20 м прослеживается неравномерное переслаивание сапропелита, разнозернистого песка с гравием и галькой и серых алевритов с прослоями невыдержанных гумусированных песков. Прослеживаются криотурбационные явления, кровля неровная, сильно окрашена гидроокисями железа. Спорово-пыльцевые спектры свидетельствуют о переотложениях верхней части микулинских межледнико- 
вых отложений, богатых пыльцой ольхи и лещины. Но в их составе быстро увеличивается участие пыльцы карликовых берез (до $70 \%$ ) и трав (до $45 \%$ ) как признак распространения валдайской перигляциальной растительности.

Верхняя часть изученного разреза характеризуется типичными смешанными спорово-пыльцевыми спектрами, состоящими из инситной части пыльцы перигляциальной растительности, а также из пыльцы и спор, переотложенных из микулинских межледниковых слоев. Участие последних так велико, что они существенно мешают прослеживанию состава перигляциальной растительности. Только интервал $15,7-16,0$ м отличается высоким содержанием пыльцы трав: 60-90\%. По традиционной интерпретации спорово-пыльцевых спектров такое явление обычно рассматривается как признак похолодания. Но в действительности может быть и наоборот. В этом интервале существенно уменьшается количество переотложенной пыльцы широколиственных пород, ольхи и лещины (до $5 \%$ каждой). В остальных случаях количество переотложенной пыльцы ольхи 5-15, лещины $10-35$, широколиственных пород 5-18\%. Кроме того, переотложена и часть пыльцы межледниковых бореальных пород - сосны и древовидных берез, которую уже невозможно более точно отличить от пыльцы сосны и березы, растущих в ледниковое время. Мысленно исключая переотложенную пыльцу термофильных и части бореальных пород из общего состава спорово-пыльцевых спектров верхней части разреза, можно убедиться, что количество пыльцы трав заметно увеличивается, достигая таких же или, может быть, еще больших величин, чем в интервале 15,7016,00 м. Уменьшение количества переотложенной пыльцы в названном интервале связано с уменьшением привноса продуктов переотложения в озерный бассейн, а также с кратковременным торфообразованием. Получена радиоуглеродная датировка этого слоя: $34800 \pm 1300$ : Tln-424 (Раямяэ, 1982). Этот слой, соответствующий, по всей вероятности, потеплению, белорусские исследователи относят к шапуровскому межстадиалу (Санько, 1981).

Выше по разрезу, на алевритах с размывом залегают бурые пески с гравием, галькой и редкими валунами. Разрез завершается фиолетово-коричневой мореной (мощность 4,5 м), которую белорусские исследователи относят к максимальной стадии валдайского оледенения.

Результаты исследования данного разреза подтверждают факт различий формирования спорово-пыльцевых спектров ледниковых и межледниковых эпох. Если интерпретация и корреляция межледниковых спектров, состоящих из инситной пыльцы, не вызывает трудностей, то расшифровка спорово-пыльцевых спектров ледниковых эпох - сложная задача. Для этого совершенно необходимо разграничение инситной и переотложенной частей спектров, что в настоящее время наиболее эффективно проводится при помощи эколого-географического анализа. Пренебрежение фактом переотложения может привести к ошибочному выделению новых межстадиалов, новых климатических оптимумов межледниковий или даже новых межледниковий. Это, несомненно, мешает стратиграфической и палеогеографической реконструкциям плейстоцена.

\section{Л И Т Е Р А У Р А}

Гричук В. П. Ископаемые флоры как палеонтологическая основа стратиграфии четвертичных отложений. - В кн.: Рельеф и стратиграфня четвертичных отложений северо-запада Русской равнины. М., 1961, 25-71.

Гричук В. П., Мальгина Е. А., Моносзон М. Х. Значение палеоботанических мате- 
ALNUS $\Rightarrow \quad$ CORYLUS

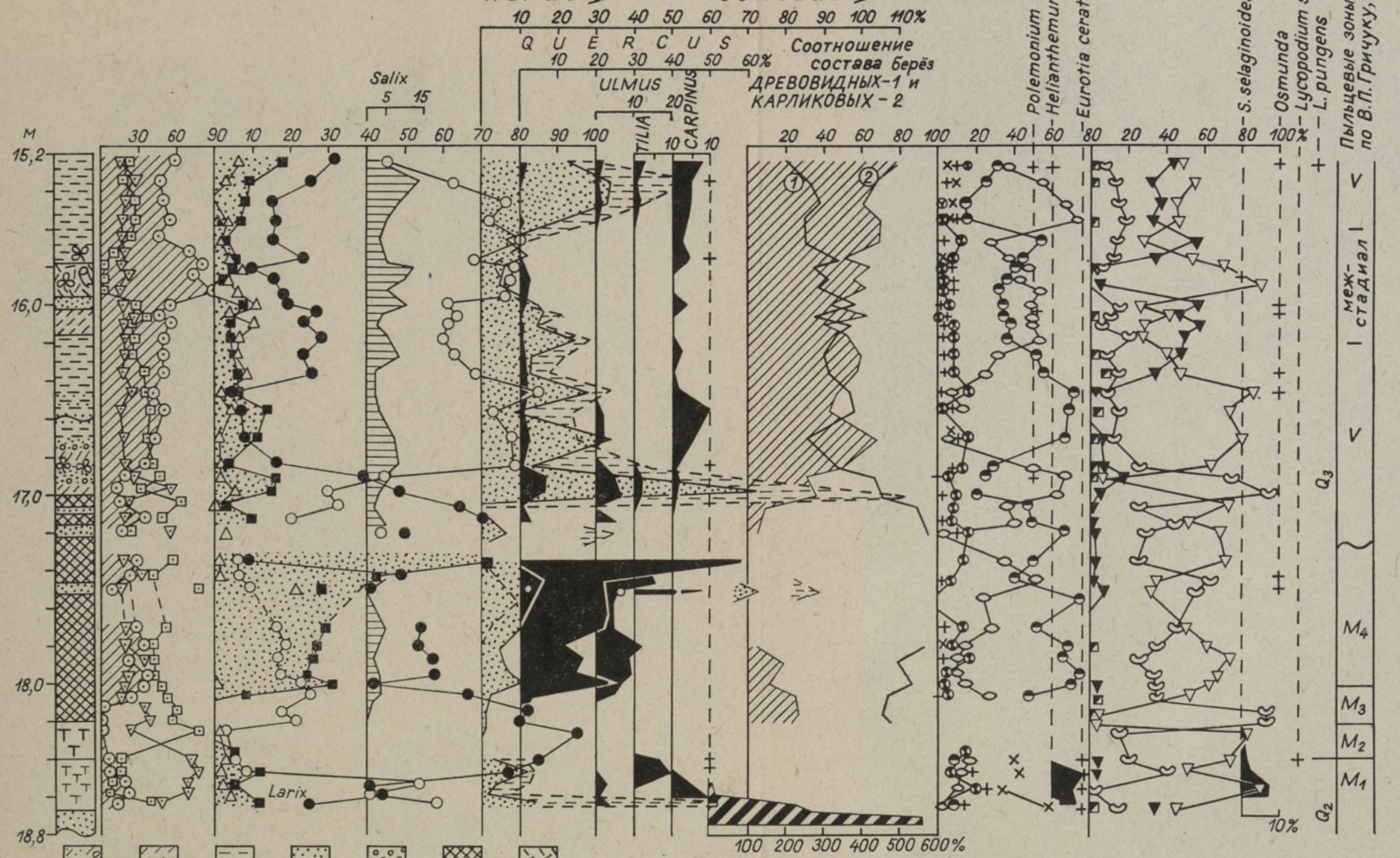

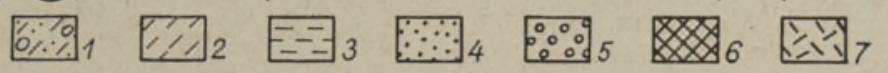

Дочетвертичные палиноморфоы

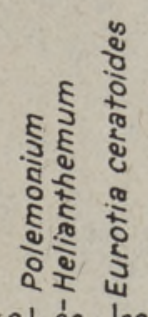

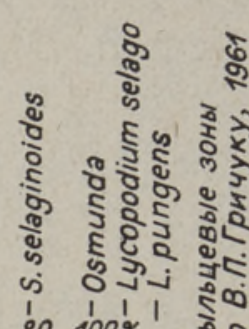

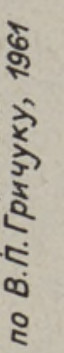

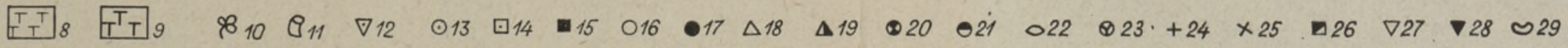

Рис. 1. Спорово-пыльцевая диаграмма отложений позднеледниковья московского оледенения, мнкулинского межледниковья и валдайской ледниковой эпохи в разрезе Коневича. Условные обозначения: 1 - морена, 2 - супесь, 3 - алеврит, 4 - песок, 5 - гравнй, 6 - сапропелит, 7 - торф, 8 голубовато-серая известь, 9 - желтовато-белая нзвесть, 10 - растительные остатки, 11 - древесина, 12 - споры, 13 - травянистые растения (NAP), 14 - древесные породы (AP); 15 - широколиственные породы (Querc. Mixt.), 16 - Betula, 17 - Pinus, 18 - Picea, $19-$ Abies, 20 - Varia, 21 - Gramineae, 22 - Cyperaceae, 23 - Ericales, 24 - Artemisia, 25 - Chenopodiaceae, 26 - Lycopodium, $27-$ Bryales, $28-$ Sphagnum, $29-$ Polypodiaceae. 

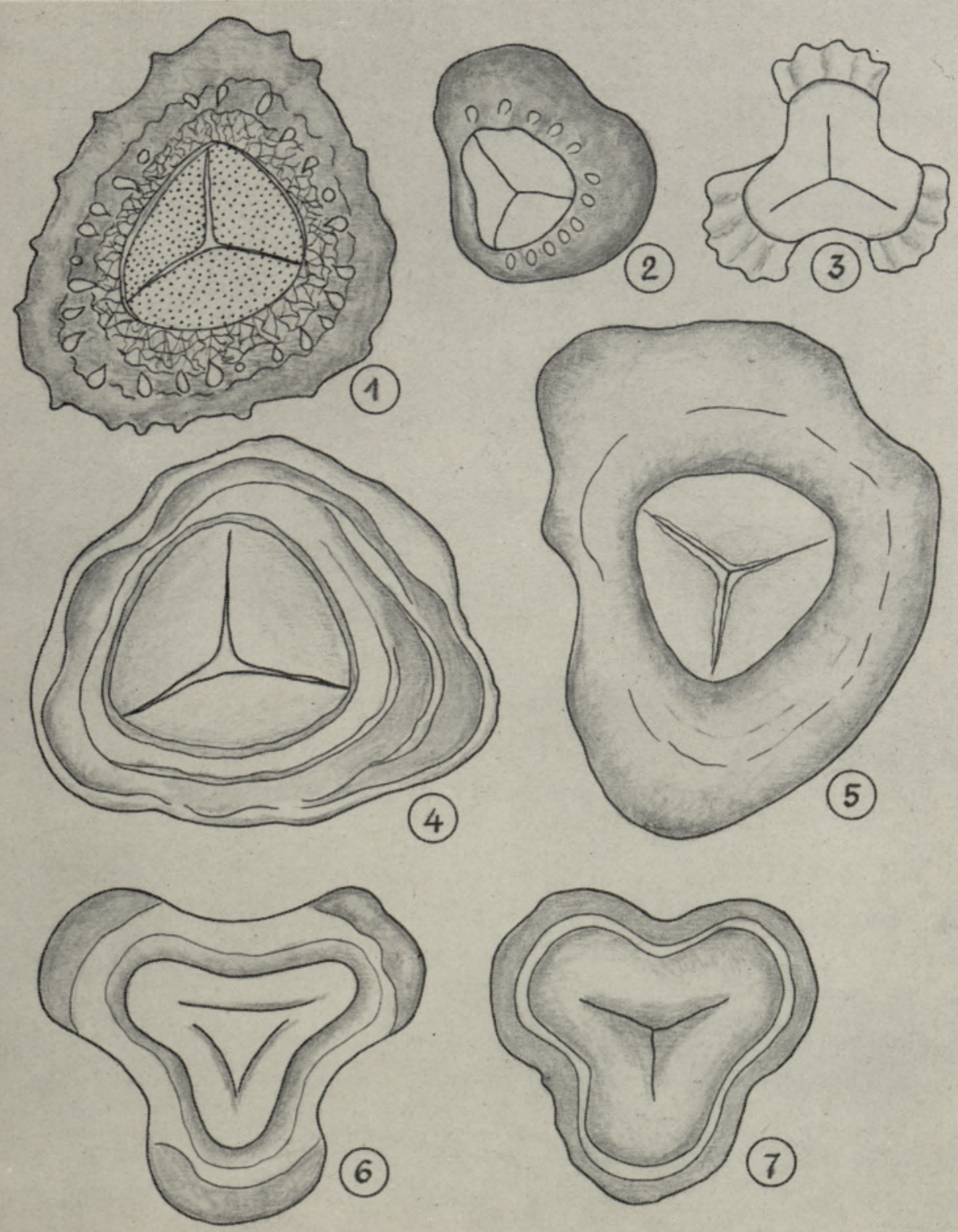

Pис. 2. Дочетвертичные палиноморфы. I-2 Trematozonotriletes sp. sp., 3 - Trilobozonotriletes sp., $4-5$ Euryzonotriletes sp., $6-7$ Simozonotriletes sp. sp., 


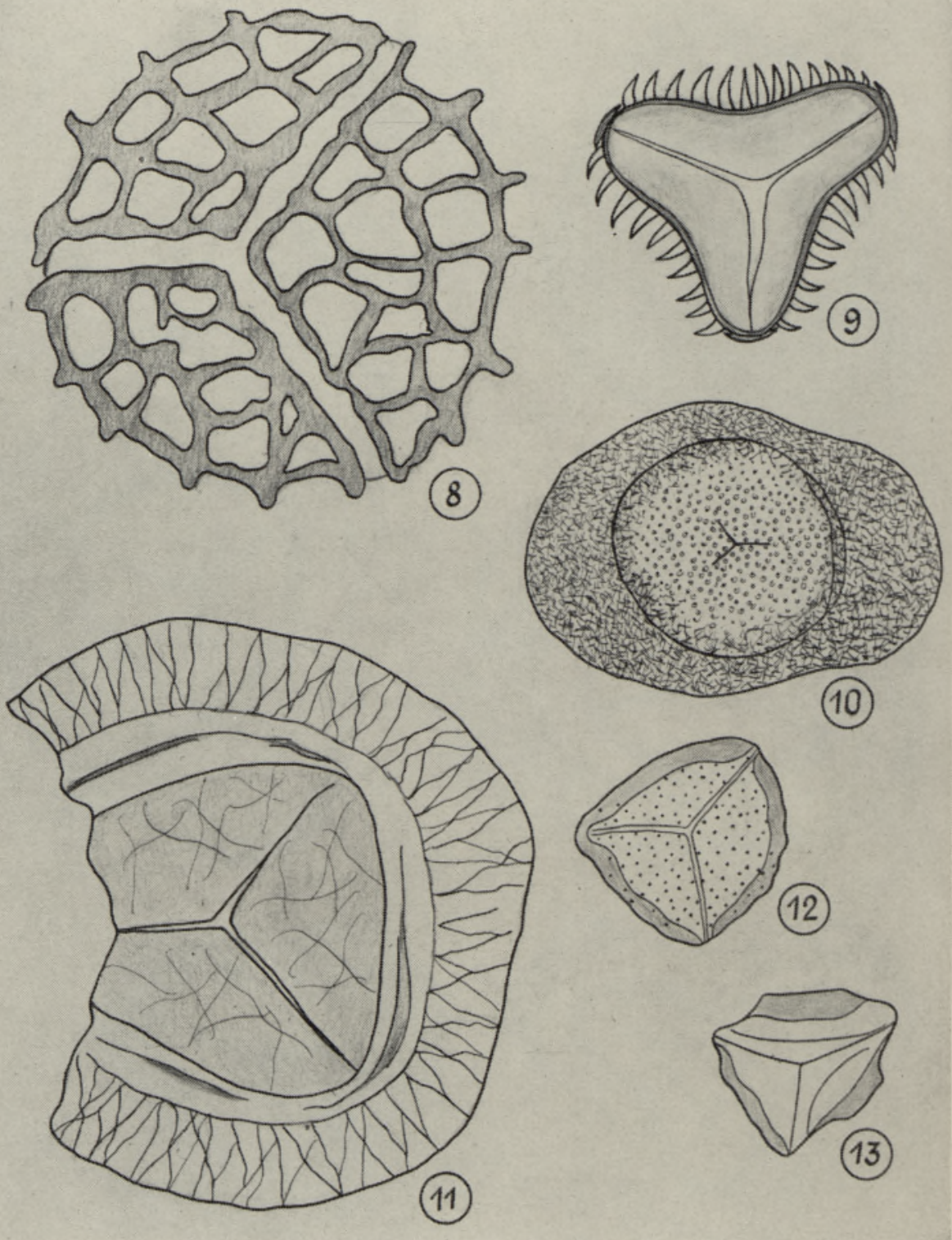

8 - Dictyozonotriletes sp., 9 - Diatomozonotriletes sp., 10 - Perisaccus primigenius Naum., 11 - Zonotriletes sp., 12 - Archaeozonotriletes sp., 13 - Gleichenia sp. 
риалов для стратиграфии валдайских отложений. - В кн.: Последннй ледниковый покров на северо-западе Европейской части СССР. М., 1969, 57-105.

Кедо Г. Н. Споры ннжнего карбона Припятского прогиба (яснополянский подъярус). - В кн.: Палеонтология и стратиграфня БССР. Минск, 1966, 3-143.

Лийвранд Э. Д. О возрасте и корреляцин слоев разрезов Пасьва и Колешки Архангельской области по геологическим и палинологическим данным. - В кн.: Геология плейстоцена северо-запада СССР. Апатиты, 1981, 72-86.

Лийвранд Э. Значение переотложенной пыльцы межледниковых термофильных древесных пород в стратиграфин. - Изв. АН ЭССР. Геол., 1982, 31, 75-79.

Раукас А., Лийвранд Э. Плейстоценовые отложення в разрезе Вяэна-Йыесуу (Северная Эстония) и их генезис. - Изв. АН ЭССР. Хим. Геол., 1971, 20, 60-72.

Раямяэ P. A. Геохронология позднего плейстоцена северо-западной части ВосточноЕвропейской равнины по данным усовершенствованного радиоуглеродного метода. - Автореф. канд. дис. Таллин, 1982.

Санько А. Ф. Краткий очерк стратиграфни неоплейстоценовых отложений СевероВосточной Белоруссии и смежных районов Смоленской области. - В кн.: Геологические исследования кайнозоя Белоруссии. Минск, 1981, 45-55.

Институт геологии

Академии наук Эстонской ССР

Поступнла в редакцию 1/VI 1983

\section{Elsbet LIIVRAND}

\section{JÅ̆VAHEAEGADE JA JÅ̆TUMISAEGADE SETETE PALUNOLOOGILISE UURIMISE METOODIKAST KONEVITŠI LÄBILOIKE (SMOLENSKI OBLAST) NAITEL}

Artiklis on näidatud õietolmuspektrite moodustumise iseärasusi jäävaheaegade ja jäätumisaegade setetes ning rōhutatud vajadust eraldada ümbersettinud vormid välja jäätumisaegsetest setetest.

\section{Elsbet LIIVRAND}

\section{ON A METHOD OF PALYNOLOGICAL INVESTIGATIONS \\ OF INTERGLACIAL AND GLACIAL DEPOSITS ON THE EXAMPLE OF THE KONEVICH SEQUENCE IN SMOLENSK REGION}

The formation of pollen spectra during the Interglacials and Glacials differed substantially. Interglacial deposits contain practically primary pollen and spores only. The Late-Glacial deposits of the Middle Pleistocene in the Konevich Sequence (Fig. 1) contain a lot of rebedded pollen and spores from both the Pre-Quaternary rocks (Figs 2, 3) and the Likhvian Interglacial layers. Deposits of the Valdaian Glacial Stage are oversaturated with rebedded pollen from Mikulian layers. In interstadial deposits the content of rebedded pollen decreased. For drawing correct stratigraphical and paleogeographical conclusions it is absolutely necessary to separate the differentaged parts of pollen spectra. At present the most effective method for it is the ecological-geographical analysis of the investigated species. 